\title{
Pelatihan Berwirausaha Sampah dan Manajemen Sampah di Desa Argorejo, Sedayu, Bantul, Yogyakarta
}

\author{
Siti Kurnia Widi Hastuti ${ }^{1}$, Fatwa Tentama ${ }^{2}$, Surahma Asti Mulasari ${ }^{3}$, \\ Triwahyuni Sukesi ${ }^{3}$, Sulistyawati ${ }^{3}$, Muchsin Maulana ${ }^{3}$ \\ 1,2,3 Universitas Ahmad Dahlan, Yogyakarta, Indonesia
}

\begin{abstract}
A B S T R A C T
ENTREPRENEURSHIP AND WASTE MANAGEMENT TRAINING IN ARGOREJO VILLAGE, SEDAYU, BANTUL, YOGYAKARTA. Ministry of Environment noted that the average population of Indonesia produces around 2.5 liters of waste per day or 625 million liters of the total population. This condition will continue to grow according to the environment. According to the Indonesian Waste Statistics (2012) the amount of waste that appears throughout Indonesia reaches 38.5 million tons per year with the dominant waste being in Java (21.2 million tons per year). Waste generation will not decrease or run out and will even continue to grow along with the growth of human population and the higher and more complex human activities. The accumulation of waste that is getting bigger from day to day will reduce space and disrupt human activities so that the human goal to improve the quality of life actually makes the quality of life decrease due to waste generation problems.Method used is to provide counseling and training directly to the general public with material for entrepreneurship motivation and waste bank management using lecture, discussion, and question and answer methods. Results obtained were the extension activities and the training went well and the participants actively participated in the extension activities to completion. Counseling is done interactively between the speakers and the participants present.
\end{abstract}

Keywords: Agriculture, Household, Waste.

\begin{tabular}{llll}
\hline Received: & Revised: & Accepted: & Available online: \\
24.09 .2019 & 07.11 .2019 & 10.01 .2020 & 14.02 .2020 \\
\hline
\end{tabular}

\section{Suggested citation:}

Hastuti, S., Tentama, F., Mulasari, S., Sukesi, T., Sulistyawati., \& Maulana, M. (2020). pelatihan berwirausaha sampah dan manajemen sampah di Desa Argorejo, Sedayu, Bantul, Yogyakarta. Jurnal Pengabdian Pada Masyarakat, 5(1), 51-58. https://doi.org/10.30653/002.202051.252

Open Access I URL: http://ppm.ejournal.id/index.php/pengabdian/article/view/252

\footnotetext{
${ }^{2}$ Corresponding Author: Program Studi Psikologi Universitas Ahmad Dahlan; Jl. Kapas, No 9, Semaki Yogyakarta 55166, Indonesia; Email: fatwa.tentama@psy.uad.ac.id
} 


\section{PENDAHULUAN}

Salah satu permasalahan besar yang dialami kota-kota besar di Indonesia adalah persampahan. Menurut data Statistik Lingkungan Hidup Indonesia (SLHI), Sampah dan limbah telah menjadi permasalahan nasional. Masalah persampahan sangat terkait dengan pertambahan penduduk, pertumbuhan ekonomi dan perubahan pola konsumsi masyarakat. Pada tahun 2017 jumlah penduduk Indonesia sudah mencapai 261,89 juta jiwa meningkat dibanding tahun 2000 yang sebesar 206,26 juta jiwa. Tren pertumbuhan ekonomi juga terus mengalami peningkatan, dengan kontribusi terbesar dari sektor manufaktur. Pertumbuhan pesat di sektor industri juga merupakan imbas dari meningkatnya pendapatan rumah tangga dan makin beragamnya pola serta jenis konsumsi masyarakat. Kondisi tersebut menimbulkan bertambahnya volume, beragamnya jenis, dan karakteristik sampah dan limbah.

Kementerian Lingkungan Hidup mencatat rata-rata penduduk Indonesia menghasilkan sekitar 2,5 liter sampah perhari atau 625 juta liter dari jumlah total penduduk. Kondisi ini akan terus bertambah sesuai dengan kondisi lingkungannya. Menurut Statistik Sampah Indonesia (2012), jumlah sampah yang muncul di seluruh Indonesia mencapai 38,5 juta ton per tahun dengan dominan sampah tersebut berada di Pulau Jawa (21,2 juta ton per tahun).

Sampah dapat diartikan sebagai konsekuensi adanya aktivitas kehidupan manusia. Timbulan sampah tidak akan berkurang atau habis bahkan akan terus bertambah seiring dengan pertumbuhan populasi manusia serta semakin tinggi dan kompleksnya kegiatan manusia. Timbulan sampah yang semakin besar dari hari ke hari akan mengurangi ruang dan mengganggu aktivitas manusia sehingga tujuan manusia untuk meningkatkan kualitas hidup justru membuat kualitas hidupnya menurun karena permasalahan timbulan sampah (Aryeti, 2011).

Edukasi masyarakat mengenai permasalahan lingkungan yang bersifat kompleks akibat timbulan sampah diprlukan untuk membentuk kesadaran masyarakat. Partisipasi aktif warga menjadi hal yang penting untuk diidentifikasikan dalam aksi pengelolaan sampah. Upaya menjaga kelestarian lingkungan harus bermula dari diri individu dengan memulai dengan melakukan hal-hal kecil. Menurut Singhirunnusorn, Donlakorn dan Kaewhanin (2012), Perubahan yang dilakukan bias menularkan kebiasaan dalam masyarakat sehingga terjadi perubahan besar. Perubahan cara berpikir masyarakat mengenai pengelolaan sampah untuk mengurangi sampah di sumber melalui partisipasi warga harus diintegrasikan ke dalam proyek bank sampah yang berbasis masyarakat.

Penanganan sampah dan limbah ini sejalan dengan target Sustainable Development Goals (SDGs) tujuan 12.5, bahwa pada tahun 2030 setiap negara secara substansial mengurangi produksi limbah melalui pencegahan, pengurangan, daur ulang, dan penggunaan kembali, untuk dapat menjamin pola produksi dan konsumsi yang berkelanjutan. Regulasi dalam menangani permasalahan sampah dan limbah tertuang dalam UU Nomor 18 tahun 2008 tentang pengelolaan sampah dan turunannya, serta Undang Undang Nomor 32 Tahun 2009 tentang Perlindungan dan Pengelolaan Lingkungan Hidup. Dalam Perpres No.97 tahun 2017, pemerintah menargetkan pengurangan sampah rumah tangga dan sampah sejenis sampah rumah tangga sebesar 30\% dan penanganannya mencapai 70\% sampai 2025 (SLHI,2018). 
Penanganan sampah dan limbah juga perlu didukung sarana dan prasarana yang memadai. Kementerian Lingkungan Hidup dan Kehutanan (KLHK) menyatakan sudah terdapat 5.244 Bank Sampah di Indonesia, sedangkan untuk pengelolaan limbah domestik, Kementerian Pekerjaan Umum dan Perumahan Rakyat (PUPR) pada tahun 2015 sudah membangun 25 Instalasi Pengolahan Air Limbah (IPAL) terpusat, 180 IPAL kawasan serta 155 Instalasi Pengolahan Lumpur Tinja (IPLT) di Indonesia (SLHI, 2018).

Bank sampah mengajarkan masyarakat untuk memilah sampah, menumbuhkan kesadaran masyarakat mengolah sampah secara bijak agar dapat mengurangi sampah yang diangkut ke TPA.Selain itu warga yang menyerahkan sampah akan memperoleh tambahan penghasilan untuk kemandirian ekonomi warga dapat digunakan untuk usaha simpan pinjam seperti koperasi, dengan bunga rendah agar keuangan bank sampah dapat diputar dan dikembangkan, juga terwujudnya kesehatan lingkungan (Donna \& Heru, 2016). Pembentukan bank sampah yang diintegrasikan dengan edukasi mengenai prinsip $4 R$ menjadi pengetahuan dasar bagi warga untuk mengelola sampah sejak dari sumbernya, yaitu sampah rumah tangga (Donna \& Heru, 2016).

Tahapan bank sampah dimulai dengan melakukan pemilahan sampah oleh nasabah sebelum di setorkan ke bank sampah, pemilahan sampah tergantung pada kesepakatan saat pembentukan bank sampah, misalnya berdasarkan kategori sampah organik dan anorganik, kemudian dilakukan penyetoran sampah ke bank dengan waktu penyetoran sampah yang telah di sepakati sebelumnya, setelah itu dilakukan penimbangan, pencatatan baru yang terakhir dilakukan pengangkutan ke pengolahan sampah (Buku Panduan Sistem Bank Sampah, 2013).

Masyarakat Desa Argorejo dengan dengan kondisi saat ini sangat memerlukan pengetahuan tentang pentingnya mengelola sampah, dampak yang di timbulkan dari limbah sampah dan manfaat apa yang bisa didapatkan dari berwirausaha sampah dan perlu diperkenalkan bank sampah. Selain itu perlu mendapat pengetahuan dan ketrampilan untuk memanfaatkan sampah melalui bank sampah, memperkenalkan bank sampah, menjalankan atau mengelola bank sampah karena ada beberapa dusun yang sudah mempunya bank sampah tetapi dalam kondisi vakum.

\section{METODE}

Mitra dari kegiatan pengabdian kepada masyarakat ini adalah Desa Argorejo, program ini melibatkan kelompok wanita tani (KWT) dan dukuh di Desa Argorejo Sedayu Bantul Yogyakarta serta mahasiswa KKN PPM bidang Kesehatan Masyarakat sebagai penanggung jawab utama. Kegiatan dilakukan bersama dengan Dosen Psikologi dan Fakultas Kesehatan Masyarakat UAD. Kegiatan pengabdian kepada masyarakat dilaksanakan pada tanggal 2 Agustus 2019, pelaksanaan kegiatan dalam pengabdian ini meliputi:

1) Penyuluhan

a. Penyuluhan Manfaat Bank sampah

b. Penyuluhan dan pelatihan "Meningkatkan Motivasi Wirausaha Sampah"

2) Pemutaran video bank sampah dan penjelasannya

Video ini memaparkan sebuah kasus yang diawali dari perilaku membuang sampah sembarangan yang akhirnya menimbulkan pencemaran lingkungan dan pada 
akhirnya solusi terbaik adalah membuang sampah dengan menabung di bank sampah

3) Pelatihan manajemen bank sampah

Menjelaskan dan melatih masyarakat bagaimana memulai mendirikan bank sampah, membentuk kepengurusan, sarana dan prasarana yang dibutuhkan masyarakat, membuat pembukuan dan laporan keuangan bank sampah dan bagaimana menjalankan bank sampah dengan efektif dan efisien.

Metode yang digunakan adalah dengan memberikan penyuluhan dan pelatihan secara langsung kepada masyarakat umum dengan materi motivasi berwirausaha sampah dan manajemen bank sampah menggunakan metode ceramah, diskusi, penanyangan video dan tanya jawab.

\section{HASIL DAN PEMBAHASAN}

Kegiatan penyuluhan dan pelatihan ini, warga masyarakat yang hadir diberi edukasi mulai dari akibat yang di timbulkan dari membuang sampah sembarangan berdampak bagi kesehatan, bahaya aroma sampah yang dihirup oleh anggota keluarga, biaya yang dikeluarkan ketika sakit akibat terpapar oleh sampah, serta cara untuk mulai melakukan tertib bank sampah atau memanajamen sampah untuk selanjutnya supaya lebih bermanfaat bagi kehidupan sehari-hari di keluarga maupun warga setempat.

Kegiatan penyuluhan dan pelatihan yang dilakukan kepada warga masyarakat diharapkan dapat memberi pengaruh untuk bisa memanfaatkan sampah untuk yang lebih baik dan mendapat keuntungan dari sampah tersebut. Warga masyarakat yang hadir diharapkan bisa menjadi pelopor atau dapat mengedukasi warga yang lainnya untuk dapat berhenti membuang sampah sembarangan, serta dapat membentuk suatu kawasan bebas sampah, tujuannya agar penyakit yang ditimbulkan oleh sampah di rumah tidak di hirup oleh anggota keluarga lainnya. Karena pada dasarnya sampah sangat berbahaya bagi kesehatan tubuh maupun kesehatan bumi.

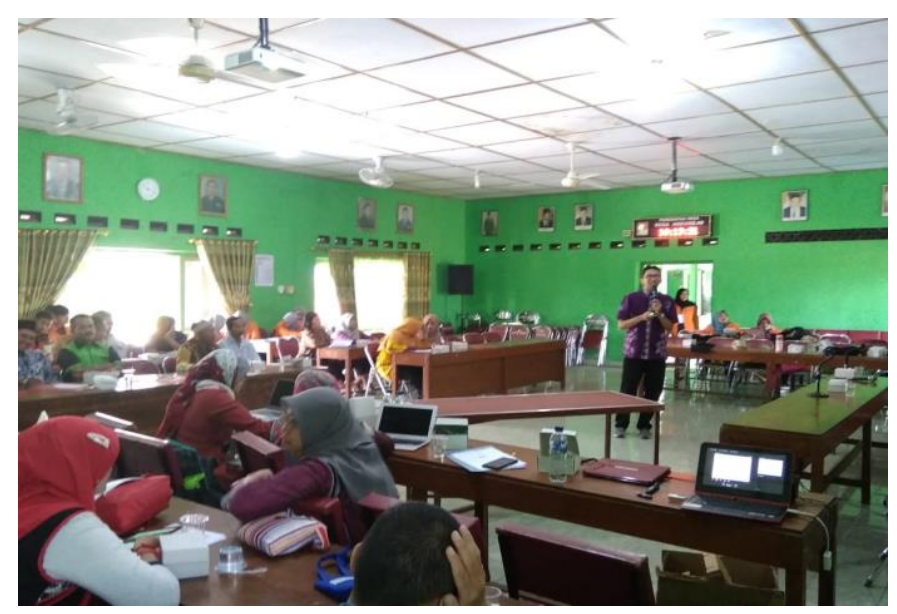

Gambar 1. Penyampaian Materi Tentang Meningkatkan Motivasi Berwirausaha

Kegiatan penyuluhan dan pelatihan kepada masyarakat ini dilakukan di Balai Desa Argorejo pada tanggal 2 Agustus 2019. Kegiatan yang dilaksanakan adalah materi 
pertama yaitu penyuluhan tentang meningkatkan motivasi berwirausaha, program ini bertujuan untuk meningkatkan motivasi diri untuk berwirausaha khususnya dalam pemanfaatan limbah/sampah peranian, peternakan, dan sampah rumah tangga serta peluang bisnis tanaan organik. Sedangkan materi penyuluhan kedua tentang manajemen bank sampah, program ini bertujuan untuk meningkatkan pemahaman, pengetahuan dan keterampilan dalam memanfaatkan sampah rumah tangga dengan metode bank sampah. Teknologi yang ditrasfer adalah berupa teknologi pengolahan sampah dengan bank sampah dan berbagai peralatan diantaranya timbangan, buku tabungan, dan buku pengurus, cara pengendaliannya menggunakan metode ceramah, diskusi, tanya jawab.

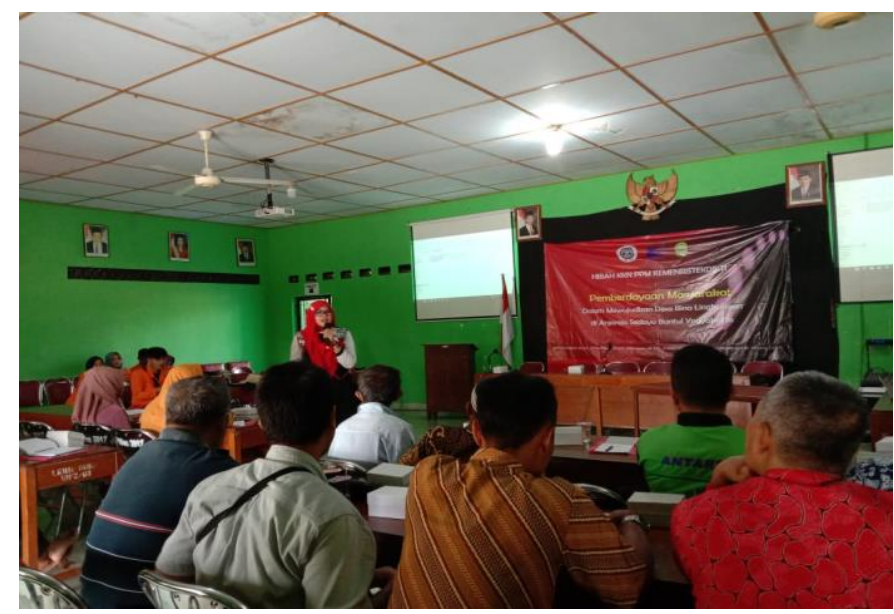
Gambar 2. Penyampaian Materi Tentang Manajemen Bank Sampah di Desa
Argorejo

Penyuluhan yang diberikan sebagian besar tentang bahaya lingkungan dari dampak sampah dan cara penanggulangannya, Menurut Davis dan Cornwell (2008) menjelaskan bahwa kata sampah padat merupakan suatu kata yang umum digunakan untuk menggambarkan sesuatu yang kita buang. Sampah padat, dimana terdiri dari bermacam benda-benda yang sudah dibuang, mengandung berbagai macam zar baik yang dapat berbahaya maupun tidak bebahaya. Akan tetapi secara umum, sampah padat yang menumpuk mampu menimbulkan dampak yang cukup serius bagi populasi manusia yang padat. Berdasarkan penjelasan tersebut, masalah sampah sebagai salah satu permasalahan lingkungan dapat dikatakan juga sebagai masalah sosial yang perlu diatur karena mempengaruhi kehidupan masyarakat luas sebagaimana dikatakan bahwa lingkungan merupakan faktor pendukung kehidupan manusia. Salah satu upaya untuk dapat menyelesaikan permasalahan sampah adalah dengan melakukan pengelolaan sampah yang bisa dilakukan dengan prinsip 3R (reduce, reuse, dan recycle). 3R adalah prinsip utama mengelola sampah mulai dari sumbernya, melalui berbagai langkah yang mampu mengurangi jumlah sampah yang dibuang ke Tempat Pembuangan Akhir (Rahmawati, 2015).

Kesadaran bahwa kesejahteraan manusia tergantung pada lingkungan menghasilkan berbagai isu lingkungan yang memerlukan data dan informasi pendukung, seperti perubahaniklim, kemerosotan keanekaragaman hayatidan 
pengelolaan sumber daya alam. Statistik lingkungan menginformasikan tentang keadaan dan perubahan kondisi lingkungan, kualitas dan ketersediaan sumber daya lingkungan, dampak dari aktivitas manusia dan peristiwa alam terhadap lingkungan, dampak perubahan kondisi lingkungan, serta tindakan sosial dan ekonomi yang diambil oleh masyarakat untuk menghindari atau mengurangi dampak tersebut dan untuk mengembalikan serta mempertahankan kapasitas lingkungan dalam menyediakan fungsi-fungsi penting bagikehidupan dan kesejahteraan manusia. Framework for The Development of Environment Statistics 2013 terdiri dari 458 statistik lingkungan yang terbagi dalam struktur yang terdiri atas enam komponen, enam komponen tersebut:

1) Kondisi dan kualitas lingkungan

2) Sumber daya lingkungan dan penggunaannya

3) Residu

4) Peristiwa ekstrim dan bencana

5) Pemukiman dan kesehatan lingkungan

6) Partisipasi, pengelolaan dan perlindungan lingkungan

Rahmawati (2015) menyebutkan bahwa sampah harus dikelola secara baik sampai sekecil mungkin agar tidak menganggu dan mengancam kesehatan masyarakat. Pengelolaan sampah yang baik, bukan untuk kepentingan kesehatan saja, tetapi juga untuk keindahan lingkungan. Pemusnahan dan atau pengelolaan sampah padat ini dapat dilakukan melalui

berbagai cara, antara lain:

1) Ditanam (Landfill),

Pemusnahan sampah dengan membuat ladang di tanah kemudian sampah dimasukkan dan ditimbun dengan tanah.

2) Dibakar (Inceneration)

Memusnahkan sampah dengan jalan membakar di dalam tungku pembakaran (incenerator).

3) Dijadikan pupuk (Composting)

Pengolahan sampah menjadi pupuk (kompos) khususnya untuk sampah organik daun-daunan, sisa makanan, dan sampah lain yang dapat membusuk.

4) Penghancuran (Pulverization)

Beberapa kota besar di Indonesia telah memiliki mobil pengumpul sampah yang dilengkapi alat pelumat sampah. Sampah yang berasal dari bak-bak penampungan langsung dihancurkan menjadi potonganpotongan kecil sehingga lebih ringkas. Sampah yang telah dilumatkan dapat dimanfaatkan untuk menimpun permukaan tanah yang rendah.

5) Makanan ternak (Hogfeeding)

Sampah organik seperti sayuran, ampas tapioka, dan ampas tahu dapat dimanfaatkan sebagai makanan ternak.

6) Pemanfaatan ulang (Recycling)

Sampah-sampah yang sekiranya masih bisa diolah, dipungut, dan dikumpulkan.

Pengelolaan sampah yang baik dan layak bukan saja dapat meninggalkan kebersihan maupun estetika lingkungan, akan tetapi juga dapat meniadakan atau 
menghambat berkembang biaknya vector berbagai penyakit menular yang dapat merugikan kesehatan masyarakat. Hal tersebut dikarenakan sampah dapat sebagai sumber makanan, sarang/tempat tinggal serta media yang baik untuk perkembangan kehidupan makhluk hidup (Rahmawati, 2015).

Potensi dampak kesehatan dan lingkungan yang ditimbulkan oleh sampah B3 rumahtangga dipengaruhi oleh kuantitas, karakteristik dan cara penanganannya (Conn, 1989). Semakin besar kuantitas SB3-RT yang dibakar sembarangan dan dibuang secara langsung ke lingkungan, semakin besar risiko terjadinya gangguan kesehatan dan pencemaran lingkungan. Cara penanganan SB3-RT yang banyak dilakukan oleh masyarakat terutama yang tinggal di perdesaan atau di wilayah yang belum mendapatkan pelayanan adalah membakar, membuang ke badan air, pekarangan rumah, lahan-lahan kosong atau tempat pembuangan sampah ilegal di lingkungan sekitar tempat tinggal (Iswanto, 2016).

Secara keseluruhan pelaksanaan kegiatan dapat berjalan dengan lancar, semua peserta aktif mengikuti penyuluhan dan pelatihan dengan bersemangat. Kegiatan penyuluhan dan pelatihan motivasi berwirausaha dan manajemen bank ini bertujuan untuk meningkatkan pengetahuan masyarakat baik orang tua ataupun remaja, khusunya untuk dapat menyadari pentingnya berperilaku hidup bersih dan sehat khususnya menjauh dari kebiasaan membuang sampah sembarangan. Jenis penyuluhan yang dilakukan cukup mudah untuk dilakukan oleh masyarakat dan mudah dipahami oleh peserta penyuluhan.

Gerakan membuang sampah pada tempatnya sangat sulit bila hanya ditegakkan dengan promosi saja, tetapi harus didasari dengan tekad individu sendiri dibantu dengan dukungan dari lingkungan. Perubahan perilaku masyarakat tidak dapat diharapkan mudah terjadi hanya dengan membuat peraturan-peraturan. Karena itu perlu diberikan pendidikan kesehatan pada masyarakat luas yang sesuai dengan budaya masyarakat setempat dengan menggunakan berbagai media yang ada. Misalnya bila di perdesaan di buat suatu leaflet dengan gambar-gambar yang menarik. Cara yang digunakan menyampaikan pesan hendaknya tidak menggurui, tetapi dipilih cara lain yang bervariasi.

Diharapkan dengan adanya penyuluhan tentang motivasi berwirausaha dan manajemen bank sampah dapat meningkatkan pengetahuan bapak-bapak, ibu-ibu dan keluarga serta masyarakat desa tersebut tentang bahayanya sampah dan bagaimana cara pengendalian perilaku membuang sampah yang aman dan berkualitas. Dengan adanya upaya peningkatan pengetahuan dan ketrampilan melalui penyuluhan dan pelatihan ini diharapkan dapat muncul sikap kesadaran dan niat untuk tidak membuang sampah sembarangan dalam sehari-hari akan tetapi di kumpulkan kepada bank sampah.

\section{SIMPULAN}

Kegiatan pengabdian masyarakat di Desa Argorejo dapat berjalan dengan baik dan lancar. Peserta antusias dan dapat bekerjasama dengan baik. Masyarakat menyadari bahwa sampah dilingkungannya ternyata dapat dimanfaatkan dan ditabung di bank 
sampah. Ketertarikan peserta di tunjukkan dari peserta yang aktif bertanya dan berdiskusi terkait dengan materi yang disampaikan.

\section{REFERENSI}

Aryenti. (2011). Peningkatan peranserta masyarakat melalui gerakan menabung pada bank sampah di Kelurahan Babakan Surabaya, Kiaracondong Bandung. Jurnal Permukiman, 6(1), 40-46.

Davis, M. L., \& Cornwell, D. A. (2008). Introduction to environmental engineering, 4 th. Ed. Singapore: McGraw-Hill International Editions.

Asteria, D. \& Heruman, H. (2016). Bank sampah sebagai alternatif strategi pengelolaan sampah berbasis masyarakat di Tasikmalaya. Jurnal Manusia dan Lingkungan, 23(1), 135141.

Utami, E. (2013). Buku panduan sistem bank sampah dan 10 kisah sukses. Jakarta: Yayasan Unilever Indonesia.

Iswanto, Sudarmadji, Wahyuni, E. T. \& Sutomo, A. H. (2016). Timbulan sampah B3 rumah tangga dan potensi dampak kesehatan lingkungan di Kabupaten Sleman, Yogyakarta. Jurnal Manusia dan Lingkungan, 23(2), 179-188.

Sulistiyorini, N. R., Darwis, R. S., \& Gutama, A. S. (2015). Partisipasi masyarakat dalam pengelolaan sampah di lingkungan Margaluyu Kelurahan Cicurug. Share Social Work Journal, 5(1), 71-80

Singhirunnusorn, W., Donlakorn, K., \& Kaewhanin, W. (2012). Household recycling behaviours and attitudes toward waste bank project: Mahasarakham municipality. Journal of Asia Behavioural Studies, 2(6), 35-47.

Statistik Lingkungan Hidup Indonesia. (2018). Pengelolaan sampah di indonesia. Jakarta, Indonesia: Badan Pusat Statistik.

\section{Copyright and License}

This is an open access article distributed under the terms of the Creative Commons Attribution 4.0 International License, which permits unrestricted use, distribution, and reproduction in any medium, provided the original work is properly cited.

(C) 2020 Siti Kurnia Widi Hastuti, Fatwa Tentama, Surahma Asti Mulasari, Triwahyuni Sukesi, Sulistyawati, Muchsin Maulana. 